\title{
Regulative feedback mechanisms in cyanobacteria-driven systems: a model study
}

\author{
Inga Hense* \\ Division of Geophysics, Department of Physical Sciences, PO Box 64, 00014 University of Helsinki, Finland
}

Present address: Baltic Sea Research Institute (IOW), Seestr. 15, 18119 Rostock, Germany

\begin{abstract}
While we have some understanding about the influence of physical processes on biological variables, our knowledge about biological-physical feedback loops in marine ecosystems is scarce. In this model study the impact of cyanobacteria on their environment and life cycle stages is assessed by a coupled biological-physical model. Several positive and negative feedback loops are identified including a short temperature-cyanobacteria-temperature loop which is embedded into longer ones running on the seasonal time scale. The short positive feedback loop leads to an increase of cyanobacteria and a simultaneous decrease of eukaryotic phytoplankton biomass in summer. However, the induced changes in the nutrient and temperature field result in enhanced eukaryotic phytoplankton growth in autumn, which degrades winter light conditions for resting spores of cyanobacteria. Nevertheless, positive feedback prevails and overall, cyanobacteria gain from their own presence. This study emphasizes the importance of considering species and life cycle characteristics in studies dealing with feedback mechanisms.
\end{abstract}

KEY WORDS: Cyanobacteria - Phytoplankton - Feedback mechanisms - Life cycle $\cdot$ Heating · Model $\cdot$ Physical-biological interactions

\section{INTRODUCTION}

Physical and biological processes in aquatic systems interact in many ways. Physical factors such as temperature and salinity, as well as processes like diffusion and advection, directly or indirectly influence biological rates and distribution of biological variables. This takes place over a wide range of temporal and spatial scales and can lead to, for example, patterns such as small-scale patchiness (Martin 2003), mesoscale variability at fronts (Hense et al. 2003) or large scale or basin-wide variations (Longhurst 1995).

However, biological processes also directly or indirectly modify the physical environment. Most notable are direct changes in optical properties, which occur during large phytoplankton blooms. First, high surface concentrations of bright phytoplankton (e.g. coccolithophores) increase the albedo, which leads to a decrease in downward penetration of solar radiation, although the global climate impact is considered to be negligible (Tyrrell et al. 1999). Second, light absorption in the water column by phytoplankton is enhanced and can therefore significantly heat the surface layer (e.g. Sathyendranath et al. 1991). Indirect modifications by phytoplankton-induced heating include changes of the mixed layer depth (e.g. Oschlies 2004) and vertical and horizontal velocities (e.g. Edwards et al. 2001) as well as an earlier breakup of sea ice and reduced sea ice concentrations (e.g. Zeebe et al. 1996, Manizza et al. 2005). It has been further proposed that the impact on thermal structure of the water column can lead to convective instabilities (Lewis et al. 1983). These changes in the physical regime might then feed back to the biota itself, though this has not been studied in detail.

Thus, these so-called biological-physical feedback loops are not well understood. The few that have been proposed are most relevant to climate. The negative feedback loop between ultraviolet radiation, DMSproducing phytoplankton, cloud formation and ultraviolet radiation (Toole \& Siegel 2004), as well as the 
positive feedback loop between iron dust input, phytoplankton concentrations, carbon export, temperature, sea-ice formation and iron dust input (Martin 1990), underlines the complexity of our climate system.

The identification of feedback loops is essential for understanding not only climate-relevant processes but also the functioning of the ecosystem. This requires, however, that key organisms and their life cycles are considered, as changes in the behaviour of organisms during part of their life history might have an impact on physical and ultimately biological processes. Cyanobacteria are a prominent example: they float to the surface during the warm summer period and can build up large surface accumulations (e.g. Kahru et al. 1994, Capone et al. 1998); consequently, a substantial change in the light climate occurs and an associated surface temperature increase has been observed (Kahru et al. 1993). Direct and indirect modifications of biological processes and thus ecosystem structure can be expected due to feedback mechanisms. Whether this results in positive or negative feedback on cyanobacteria themselves is not obvious due to the involvement of different life cycle stages, the seasonal cycle and pelagic-benthic coupling in shallow areas.

The goal of this paper is thus to identify possible feedback loops and to eventually understand the impact of cyanobacteria on their environment and themselves. This is done by using a cyanobacteria life cycle model coupled to a physical-chemical model including eukaryotic phytoplankton (Hense \& Beckmann 2006).

\section{MODEL}

To study the impact of cyanobacteria on their environment the cyanobacteria life cycle model by Hense \& Beckmann (2006) is applied. Within a 1-dimensional framework the model has been used to study the effect of life cycle on cyanobacteria bloom formation for a seasonal and interannual cycle, without taking into account feedback mechanisms. The coupled biological-physical model comprises temperature $(\mathrm{T})$, eukaryotic phytoplankton $(\mathrm{P})$, nitrogen $(\mathrm{N})$, detritus (D) and 4 cyanobacteria life cycle stages, which include trichomes (filaments) comprising only vegetative cells $(\mathrm{V})$ and both vegetative cells and heterocysts $(\mathrm{H})$, akinetes (A) and recruiting cells (R). The cyanobacteria life cycle model thus focuses on heterocyst forming filamentous cyanobacteria that also produce akinetes (see Hense \& Beckmann 2006). The transition between the individual life cycle stages is a result of changes in the internal nitrogen and energy quota. All life cycle stages migrate in the water column, but with different velocities and directions. While both vegetative life cycle stages are weakly positively buoyant $\left(0.1 \mathrm{~m} \mathrm{~d}^{-1}\right)$, akinetes sink $\left(10 \mathrm{~m} \mathrm{~d}^{-1}\right)$ and recruiting cells rise $\left(1 \mathrm{~m} \mathrm{~d}^{-1}\right)$ (Hense \& Beckmann 2006). Growth, nitrogen uptake and fixation are temperature dependent with maximum values at temperatures of around $30^{\circ} \mathrm{C}$ and controlled by the internal quotas.

Eukaryotic phytoplankton are regarded as passive in the model (i.e. without vertical migration) and growth is a function of light, temperature and nitrogen availability. Mortality losses of both eukaryotic phytoplankton and cyanobacteria are transferred into a detritus compartment. For specifying eukaryotic phytoplankton and cyanobacteria export production separately the detritus compartment has been split in this current version into eukaryotic phytoplankton $\left(\mathrm{D}_{\mathrm{P}}\right)$ and cyanobacteria derived detritus $\left(D_{C}\right)$. The sinks for detritus are remineralisation and deposition. The former is in turn a source for nitrogen.

The physical model has 50 layers, a resolution of $1 \mathrm{~m}$ and represents a near-coast water column in the mid-latitudes, e.g. the Baltic Sea. The model is forced with annual cycles of solar radiation and atmospheric temperatures. The latter prescribes a typical seasonal cycle for mid-latitudes, with a relatively rapid surface warming in spring and early summer and a gradual cooling in autumn and winter.

All biological state variables are expressed in terms of nitrogen $\left(\mathrm{mmol} \mathrm{m}^{-3}\right)$. The coupled biological-physical-chemical model, which includes 9 compartments as detailed above $\left(T, P, N, V, H, A, R, D_{P}, D_{C}\right)$ needs a 6 yr spin up to reach a time-dependent equilibrium reflecting a realistic seasonal cycle of the mixed layer dynamics, eukaryotic phytoplankton and cyanobacteria. For a detailed model description of the cyanobacteria life cycle model and results of the seasonal cycle of the biological and physical-chemical variables the reader is referred to Hense \& Beckmann (2006); the model philosophy can be found in Beckmann \& Hense (2004).

The model is thus suitable for a study addressing the relationship between cyanobacteria and their environment. However, to elucidate the feedback mechanisms between biology and physics, the warming of water by light absorption of eukaryotic phytoplankton and cyanobacteria has been included:

$$
\frac{\partial T}{\partial t}=\frac{1}{\rho \cdot c_{\rho}} \cdot \frac{\partial I}{\partial z}
$$

where $\partial T / \partial t$ denotes the temperature changes due to attenuation, $\mathrm{C}_{\rho}$ the specific heat capacity of water, $\rho$ the density of water, $I$ the irradiance and $z$ the depth. In nature, part of the absorbed light is used by eukaryotic phytoplankton and cyanobacteria to build up organic biomass through photosynthesis and part is released in the form of fluorescence and heat. Fluorescence, how- 
ever, mostly converts to heat and the part of absorbed energy which is stored in biomass is generally small, such that it can be ignored (Lewis et al. 1983 and references therein) at least in idealized or conceptual model studies. Therefore, it is assumed that the whole light absorption leads to heating of the water.

While the effect of cyanobacteria on their environment could be easily assessed in model experiments with and without cyanobacteria, the investigation of feedback mechanisms requires specific model setups. Three experiments are thus conducted to evaluate the feedback and impact of cyanobacteria on their environment and their own life cycle:

First, a simulation experiment is carried out in which the model is run without cyanobacteria. In this so-called uncoupled model run, only eukaryotic phytoplankton can retroact on their environment and themselves, which differs from a previous experiment conducted by Hense \& Beckmann (2006). In a second experiment the profiles of temperature, eukaryotic phytoplankton, nitrogen, eukaryotic phytoplankton detritus as well as the depth of the mixed layer from the uncoupled model experiment are used as the environment for cyanobacteria. In this 1-way coupled (1WAY) run, T, P, N, D and mixed layer depth are identical to the uncoupled model run. The cyanobacteria evolve within the given environment and any feedback of cyanobacteria is therefore excluded. This means that in this experiment the mass balance is not correct, due to nitrogen uptake and fixation by cyanobacteria. It is therefore not a realistic simulation of a natural system. However, it is an appropriate way to identify and qualitatively evaluate the feedback mechanisms of cyanobacteria on themselves. The third model setup includes the fully 2-way coupled (2WAY) model comprising the physicalbiological and the cyanobacteria life cycle model. In this version, cyanobacteria induced feedback is enabled and all variables can retroact, including the effects of cyanobacteria on the light climate and the nutrient field.

The results from the perpetual seasonal cycle of the uncoupled, 1WAY and the 2WAY model experiments are compared, to elucidate the feedback mechanisms between cyanobacteria, eukaryotic phytoplankton, nutrients and physics.

\section{RESULTS}

\section{Seasonal cycle of biological and physical-chemical variables}

The biological and physical variables show a pronounced seasonal cycle (Fig. 1b) similar to the model experiments presented in Hense \& Beckmann (2006).
Some smaller differences occur as a result of changes in the temperature field due to light absorption by eukaryotic phytoplankton, which is considered in this study.

With increasing solar radiation and warming of the upper surface layers the mixed layer rapidly shallows (Fig. 1b). As a result of favourable light conditions and high surface nutrient concentrations from deep winter mixing, eukaryotic phytoplankton start to grow. The eukaryotic phytoplankton spring bloom diminishes with decreasing nutrient availability. The depletion of nitrogen at the surface leads to enhanced growth at the nutricline and the formation of a subsurface eukaryotic phytoplankton maximum (see below). An increase in temperature and irradiance promotes the development of cyanobacteria: recruiting cells, which rise to the surface, become filaments with vegetative cells (V) due to a refilled energy quota. But the low nitrogen quota of these cells leads to a transfer into filaments with vegetative cells and heterocysts $(\mathrm{H})$, which are able to fix dinitrogen gas. They bypass nitrogen limitation in that way and can build up high biomass, partly due to growth and partly due to transfer from the other life cycle stages (Fig. 1a). In autumn, when solar radiation and temperature decrease, a transfer from $\mathrm{H}$ into akinetes takes place and these sink to the bottom. The mixed layer deepens and there is a small increase in eukaryotic phytoplankton again due to enhanced nutrient availability

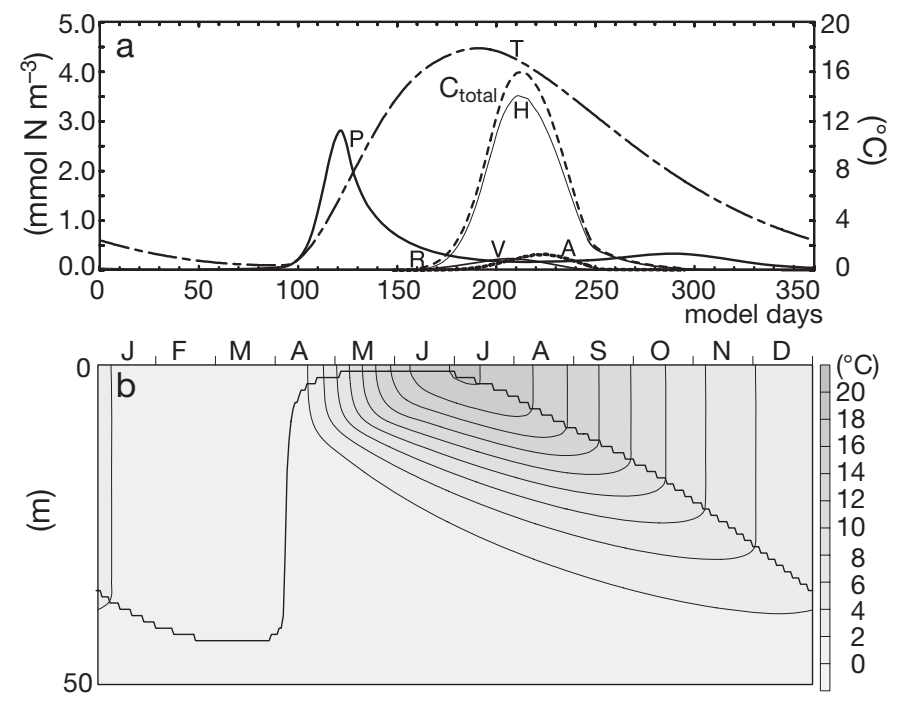

Fig. 1. (a) Seasonal cycle in the 1-way coupled model run of daily means of temperature (T), eukaryotic phytoplankton (P), cyanobacteria (C) as well as their individual life cycle stages filaments comprising vegetative cells (V) and vegetative cells and heterocysts $(\mathrm{H})$, akinetes $(\mathrm{A})$ and recruiting cells $(\mathrm{R})$ in the upper $5 \mathrm{~m}$. (b) Phase plot of temperature as a function of depth from January to December; solid line denotes mixed layer depth defined by $0.1^{\circ} \mathrm{C}$ deviation from surface value 
from mixing and remineralisation of dead organic material. In winter, deep mixing prevents eukaryotic phytoplankton from building up high biomass. The akinetes of cyanobacteria stay in the bottom layer and mature and become recruiting cells when their internal nitrogen quota is filled in the following spring.

\section{Cyanobacteria-induced direct changes}

The immediate effect of cyanobacteria on their environment is the significant change in the light climate during their bloom. Clearly, this happens during the summer months when cyanobacteria are maximum at the surface. As part of their life cycle they float and therefore accumulate in the top layers. The resulting higher absorption of light at the surface implies that only a smaller fraction of light penetrates into the deeper layers. This first order effect, however, induces a series of indirect effects.

An increase of surface temperature of ca. $0.12^{\circ} \mathrm{C}$ during the formation of the summer cyanobacteria bloom can be seen by comparing the uncoupled, 1WAY and 2WAY simulation experiments (Fig. 2). The shading by cyanobacteria further causes a cooling of the water column below. The warmer temperatures at the top and lower temperatures in the deeper layers enhance the stratification and shallow the mixed layer by $0.5 \mathrm{~m}$ (Fig. 2) in the 2WAY model run.

The combined effect of warming and shallowing of the mixed layer stimulates in turn the growth of
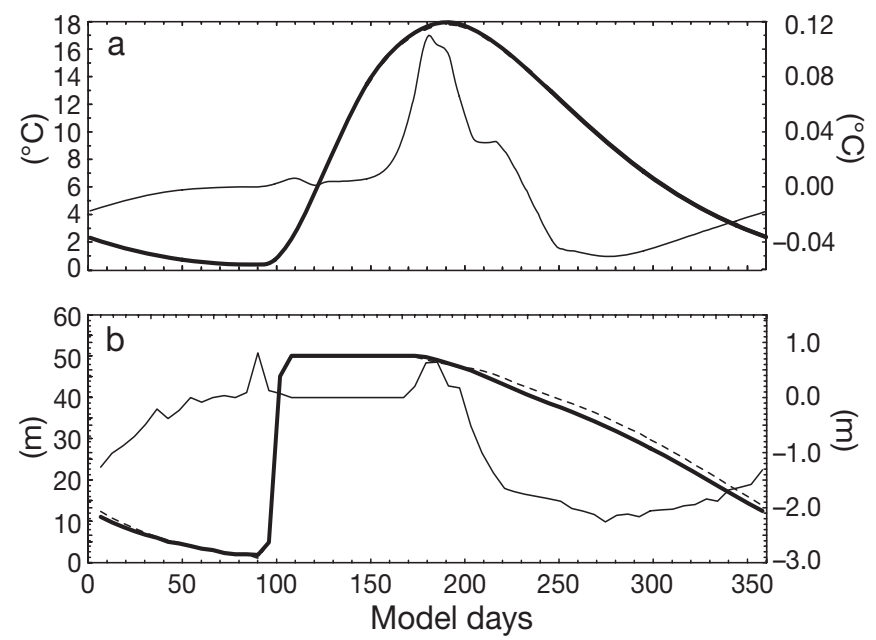

Fig. 2. Seasonal cycle of (a) daily mean of temperature in the upper $5 \mathrm{~m}$, and (b) the weekly mean of the mixed layer depth in the uncoupled, 1WAY (dotted line) and 2WAY (bold solid line) model runs. Overlaid are differences of temperature (a) and mixed layer depth (b) between 2WAY and uncoupled, 1WAY model runs (thin solid lines, right axis). Positive values of differences in mixed layer depth mean a shallowing, negative deepening cyanobacteria. Higher abundance of cyanobacteria ( 5 vs. $4 \mathrm{mmol} \mathrm{m}^{-3}$ ) can thus be seen in the experiment that includes the cyanobacteria-temperature-cyanobacteria feedback loop (Fig. 3).

The shading of the water column by cyanobacteria also has significant consequences for eukaryotic phytoplankton. Subsurface growth is now more light limited and thus, the deep eukaryotic phytoplankton maximum is less pronounced in the 2WAY compared to the uncoupled and 1WAY experiment (Fig. 4). The reduced eukaryotic phytoplankton growth leads to a significantly shallower nutricline during the summer by ca. $6 \mathrm{~m}$ (Fig. 5). This is additionally promoted due to N-fixation, decay and remineralisation of cyanobacteria in the 2-way coupled model run.

Filaments comprising vegetative cells and heterocysts gain from their own feedback. A significant increase in their biomass (by almost $1 \mathrm{mmol} \mathrm{m}^{-3}$ ) as well as in the nitrogen fixation rate (by ca. $1 \mathrm{mmol} \mathrm{m}^{-3} \mathrm{~d}^{-1}$ ) can be seen in the 2WAY experiment (Fig. 6, Table 1).

\section{Cyanobacteria-induced indirect changes}

Both processes, the cooling of the water column below the surface bloom and the shallower nutricline in the 2WAY compared to the uncoupled and 1WAY experiment, lead to a deeper mixed layer of $>1 \mathrm{~m}$ and earlier nutrient replenishment in the surface layer in autumn in the 2WAY model run. The earlier nutrient availability more than compensates the negative effect of a deeper mixed layer as can be seen in the increase of the eu-
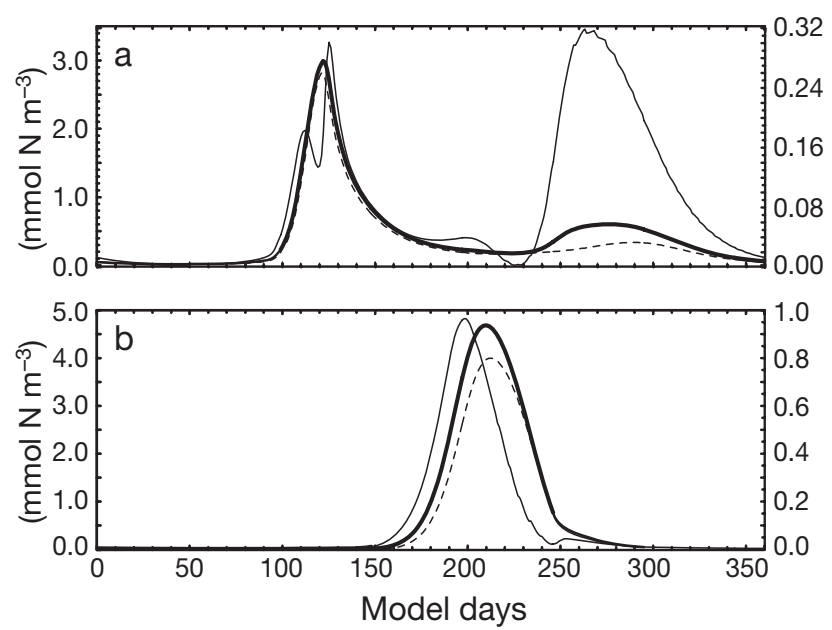

Fig. 3. Seasonal cycle of daily means of (a) eukaryotic phytoplankton and (b) cyanobacteria in the upper $5 \mathrm{~m}$ in the 1WAY (bold dashed line) and 2WAY (bold solid line) coupled experiments. Overlaid are the differences of (a) eukaryotic phytoplankton and (b) cyanobacteria between 2WAY and 1WAY models runs (thin solid line, right axis). Units are the same on left and right axis 


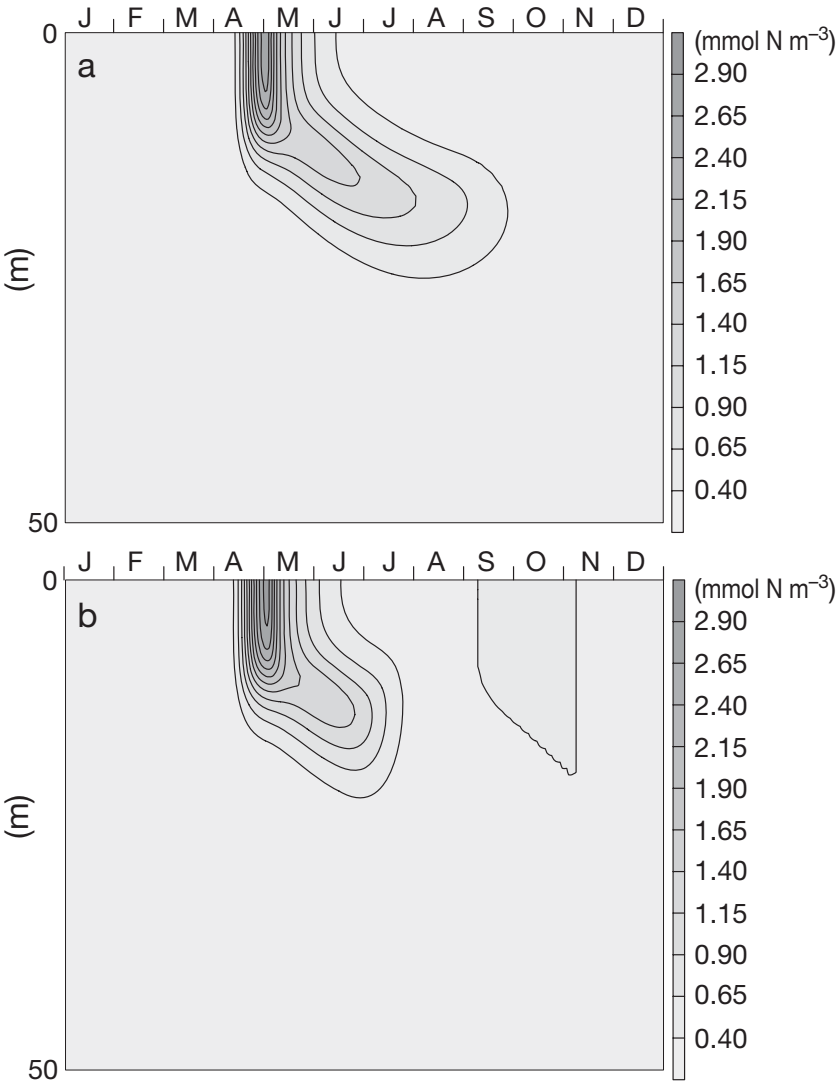

Fig. 4. Phase plots of eukaryotic phytoplankton as a function of depth from January to December in the uncoupled, 1WAY (a) and 2WAY (b) coupled model run

karyotic phytoplankton biomass by a factor of 2 in the 2WAY experiment (Fig. 3). The enhanced phytoplankton concentration in autumn has 2 indirect consequences.

First, the abundance of eukaryotic phytoplankton stays higher during the whole winter period in the 2WAY model run and results in an earlier and slightly elevated spring bloom (Fig. 3). The associated higher light absorption causes a warming of the surface and, similar to the cyanobacteria bloom, a shallower mixed layer $(1 \mathrm{~m})$ in the 2WAY experiment (Fig. 2).

Second, the larger eukaryotic phytoplankton biomass in autumn in the 2WAY model run shades the water column. The higher concentrations of phytoplankton are present throughout the winter and in this way affect the winter light conditions below the surface layers. The overwintering resting spores of cyanobacteria in the bottom layer receive less energy and more time is needed to fill their internal nitrogen quota. Thus, akinetes during the winter have to pay for the gain of filaments with vegetative cells and heterocysts in summer. Nevertheless, more akinetes are produced during the summer in the 2WAY compared to the 1WAY experiment and these ensure the formation

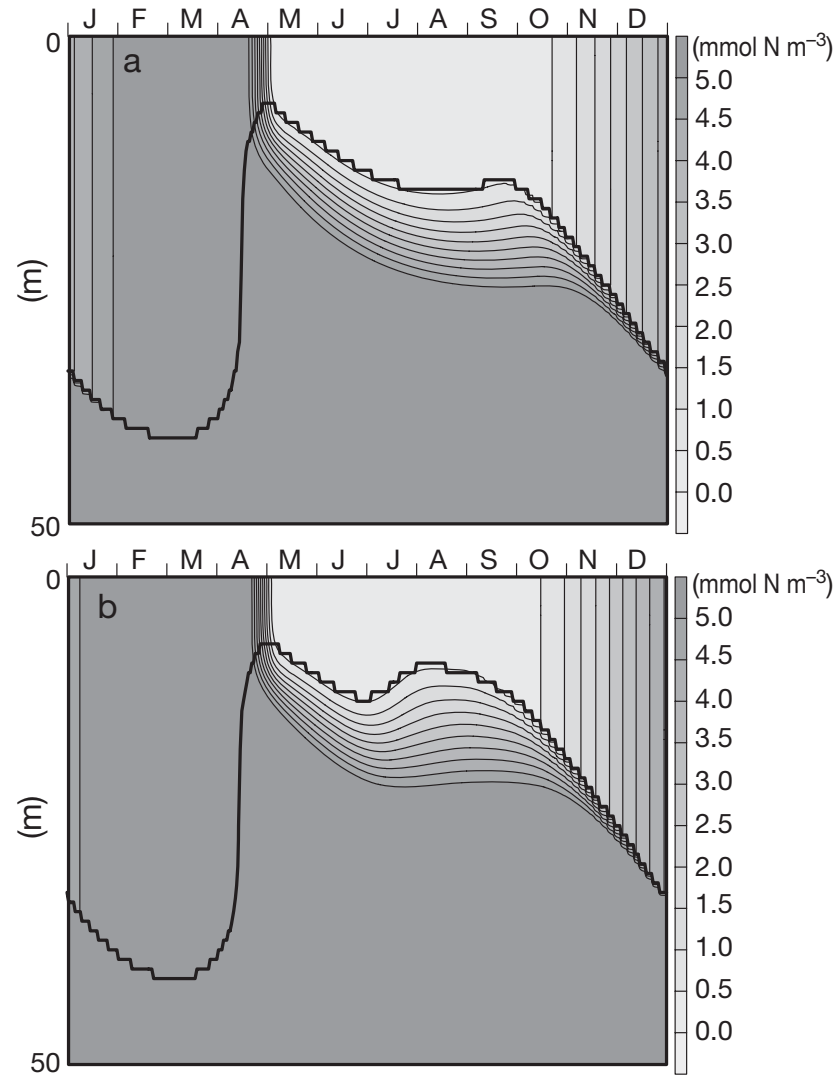

Fig. 5. Phase plots of nitrogen concentrations as a function of depth from January to December in the uncoupled, 1WAY (a) and 2WAY (b) coupled model runs. Solid line denotes nutricline depth as defined by the $0.5 \mathrm{mmol} \mathrm{m}^{-3}$ deviation from the surface value

of the cyanobacteria bloom in summer, which starts earlier due to light absorption and resulting warmer temperatures in the 2WAY run (Fig. 3).

Ultimately, cyanobacteria gain from their own induced feedback and thus a mean annual increase in cyanobacteria biomass of ca. $12 \%$ can be seen in the 2WAY simulation experiment (see Table 1). In contrast, eukaryotic phytoplankton concentrations slightly de-

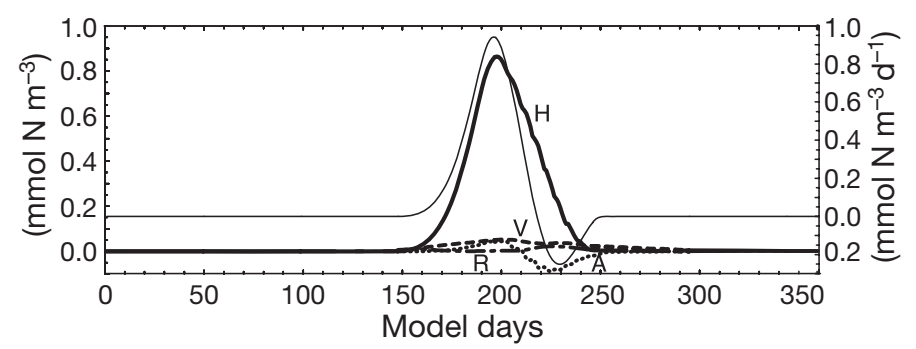

Fig. 6. Seasonal cycle of differences in daily mean of cyanobacteria life cycle stages (bold lines) in the upper $5 \mathrm{~m}$ (left axis) and nitrogen fixation rate (thin line, right axis) between the $2 \mathrm{WAY}$ and the $1 \mathrm{WAY}$ model runs 
Table 1. Annual and vertical means of temperature, vertically integrated and annual means of eukaryotic phytoplankton and total cyanobacteria and annually and vertically integrated export production and nitrogen fixation rates in the uncoupled, 1WAY and 2WAY experiments

\begin{tabular}{|lcr|}
\hline & uncoupled/1WAY & 2WAY \\
\hline Temperature; ${ }^{\circ} \mathrm{C}$ & 3.40 & 3.23 \\
Phytoplankton (eukaryotic); $\mathrm{mmol} \mathrm{m}^{-2}$ & 9.71 & 9.09 \\
${\text { Cyanobacteria (floating stages); } \mathrm{mmol} \mathrm{m}^{-2}}_{\text {Sedimentation rate (phytoplankton); } \mathrm{mmol} \mathrm{m}^{-2} \mathrm{yr}^{-1}}$ & 6.37 & 7.25 \\
Sedimentation rate (cyanobacteria); $\mathrm{mmol} \mathrm{m}^{-2} \mathrm{yr}^{-1}$ & 0.71 & 0.48 \\
Nitrogen fixation (cyanobacteria); $\mathrm{mmol} \mathrm{m}^{-2} \mathrm{yr}^{-1}$ & 198.86 & 0.85 \\
& & 220.66 \\
\hline
\end{tabular}

crease. The improved growth conditions in autumn and spring cannot compensate for the negative effect in summer, where the shading of cyanobacteria reduces the subsurface growth of eukaryotic phytoplankton. The cyanobacteria-induced changes in optical properties additionally lead to temperature modifications. In summer, cyanobacteria blooms act as a heat pump by redistributing the heat from deeper into the uppermost layers. This modifies the atmosphere-ocean heat exchange so that the annual and vertical mean temperature in the water column is lower by $0.17^{\circ} \mathrm{C}$ in the $2 \mathrm{WAY}$ compared to the uncoupled or $1 \mathrm{WAY}$ experiment (Table 1). This equates to a heat loss of $1.14 \mathrm{~W} \mathrm{~m}^{-2}$, which is consistent with estimates from previous model studies including only phytoplankton (Oschlies 2004).

\section{DISCUSSION}

In this model study, the effects of cyanobacteria on their environment and their life cycle stages have been elucidated and the interactions between the 4 components-eukaryotic phytoplankton, cyanobacteria, nutrients and physics (temperature and mixed layer dynamics) - assessed for the first time. In a series of numerical experiments positive and negative biological-physical feedback loops have been identified (Fig. 7).

The first feedback loop occurs in summer and begins with an increase in cyanobacteria biomass, in particular of filaments with vegetative cells and heterocysts. The positive buoyancy of this vegetative life cycle stage leads to an accumulation of biomass near the surface and to a significant rise in the light absorption and thus surface temperature. In this way, biological processes retroact on physical processes. Such an increase of surface temperature has been noticed during large cyanobacteria blooms (Kahru et al. 1993). The enhanced temperatures again favour the growth of cyanobacteria, thereby completing the positive and short summer cyanobacteria-temperature-cyanobacteria feedback loop (Loop I in Fig. 7).

This short feedback loop, however, is embedded into a longer one including the seasonal cycle and life cycle. The larger amount of filaments comprising vegetative cells and heterocysts produces more resting spores in autumn, when the environmental regime is unfavourable to supporting further growth. More akinetes in turn mean more recruitment and trichomes with vegetative cells in the next seasonal cycle. This second positive cyanobacteria life cycle loop (Loop II) could amplify the first one.

A third loop, however, mitigates the effects of the previous loops. The induced changes in summer nutrient conditions and subsurface temperature fields, which lead to earlier mixing and nutrient replenishment, favour eukaryotic phytoplankton growth in autumn, cause deterioration in subsurface light conditions and decelerate the maturation of akinetes. This prolonged maturation time (Loop III) counteracts but does not balance the positive feedback (Loops I \& II).

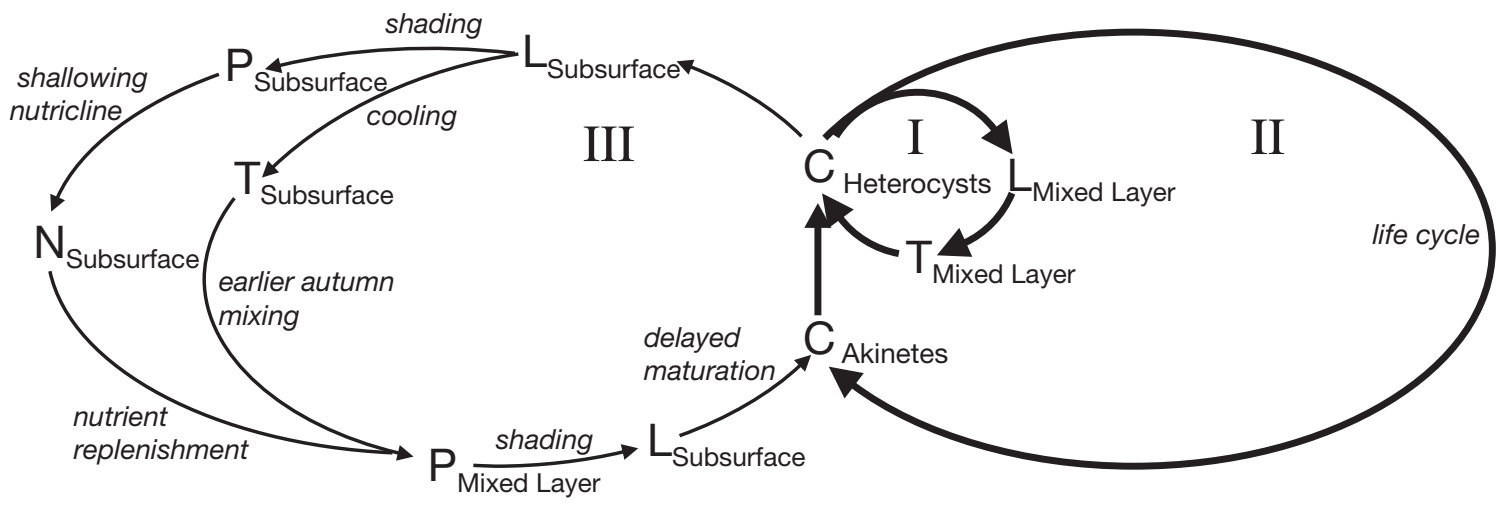

Fig. 7. Schematic presentation of feedback loops (bold line, clockwise: positive feedback loops; thin lines, counterclockwise: negative feedback loop) 
The result is a slightly higher concentration of cyanobacteria integrated over the year and depth in the model experiment in which feedback by cyanobacteria is allowed (Table 1).

The feedback loops described act simultaneously, leading to a repetitive seasonal cycle for biological and physical variables. Although conceivable, the model does not show bi-annual periodic behaviour in which cyanobacteria and eukaryotic phytoplankton alternate in amplitude between years.

Several of the above mentioned feedback loops are not restricted to cyanobacteria. Effects of the modifications of vertical thermal structure of the water column have also been demonstrated for eukaryotic phytoplankton. It has been shown that spring bloom phytoplankton promote their own growth conditions by increasing temperature (akin to cyanobacteria in Loop I) and by accelerating the shallowing of the mixed layer, which leads to an earlier spring bloom (Oschlies 2004). The results presented here show that another factor may also contribute: elevated eukaryotic phytoplankton concentrations during winter caused by a more pronounced autumn bloom additionally contribute to an early start.

Significant biologically induced heating will occur wherever we find accumulations of biomass, which includes subsurface maxima, e.g. Lewis et al. (1983). However, the largest effect can be expected from buoyant species near the surface. This emphasizes the importance of considering the characteristics of organisms in studies dealing with feedbacks. The same holds for the life cycle of the organisms. This study indicates that the life cycle dynamics prevent an excessive increase of cyanobacteria. Such a life cycle with pelagic and benthic stages will be most important in shallow areas where the associated feedback mechanisms will significantly affect physical processes and ecosystem structure. Linked to these alterations are changes of the biogeochemical cycle: both the nitrogen input through nitrogen fixation and the sedimentation rate are enhanced by cyanobacteria induced feedback mechanisms (Table 1).

Besides cyanobacteria, a number of other species may influence and shape the ecosystem by similar feedback mechanisms. So far, the group of harmful algae is mainly considered with respect to their harmfulness. However, many of these species have characteristics that might induce similar environmental changes to those explored here. Their high abundance in coastal regions, the tendency of many species to discolour the surface, and to modify the viscosity of the fluid, as well as their life cycle having pelagic and benthic stages, implies that harmful algae might have an impact on the environment through similar feedback loops.

Acknowledgements. The author gratefully acknowledges the encouraging discussions and critical review by A. Beckmann as well as the valuable comments made by 3 anonymous reviewers.

\section{LITERATURE CITED}

Beckmann A, Hense I (2004) Torn between extremes: the ups and downs of phytoplankton. Ocean Dyn 54:581-592

Capone DG, Subramaniam A, Montoya JP, Voss M, Humborg C, Johansen AM, Siefert RL, Carpenter EJ (1998) An extensive bloom of the $\mathrm{N}_{2}$-fixing cyanobacterium Trichodesmium erythraeum in the central Arabian Sea. Mar Ecol Prog Ser 172:281-292

Edwards AM, Platt T, Wright DG (2001) Biologically induced circulation at fronts. J Geophys Res C 106:7081-7095

Hense I, Beckmann A (2006) Towards a model of cyanobacteria life cycle. Ecol Model 195:205-218

Hense I, Timmermann R, Beckmann A, Bathmann UV (2003) Regional ecosystem dynamics in the ACC: simulations with a three-dimensional ocean-plankton model. J Mar Syst 42:31-51

Kahru M, Leppaenen JM, Rud O (1993) Cyanobacterial blooms cause heating of the sea surface. Mar Ecol Prog Ser 101:1-7

Kahru M, Horstmann U, Rud O (1994) Satellite detection of increased cyanobacteria blooms in the Baltic Sea: natural fluctuation or ecosystem change? Ambio 23:469-472

Lewis MR, Cullen JJ, Platt T (1983) Phytoplankton and thermal structure in the upper ocean: consequences of nonuniformity in chlorophyll profile. J Geophys Res 88:2565-2570

Longhurst A (1995) Seasonal cycles of pelagic production and consumption. Prog Oceanogr 36:77-167

Manizza M, Quéré CL, Watson AJ, Buitenhuis ET (2005) Biooptical feedbacks among phytoplankton, upper ocean physics and sea-ice in a global model. Geophys Res Lett 32, doi:10.1029/2004GL020778

Martin AP (2003) Phytoplankton patchiness: the role of lateral stirring and mixing. Prog Oceanogr 57:125-174

Martin JH (1990) Glacial-interglacial $\mathrm{CO}_{2}$ change: the iron hypothesis. Paleoceanogr 5:1-13

Oschlies A (2004) Feedbacks of biotically induced radiative heating on upper-ocean heat budget, circulation, and biological production in a coupled ecosystem circulation model. J Geophys Res 109, doi:10.1029/2004JC002430

Sathyendranath S, Gouveia AD, Shetye SR, Ravindran P, Platt $T$ (1991) Biological control of surface temperature in the Arabian Sea. Nature 349:54-56

Toole DA, Siegel DA (2004) Light-driven cycling of dimethylsulfide (DMS) in the Sargasso Sea: closing the loop. Geophys Res Lett 31, doi:10.1029/2004GL019581

Tyrrell T, Holligan PM, Mobley CD (1999) Optical impacts of oceanic coccolithophore blooms. J Geophys Res 104: $3223-3241$

Zeebe R, Eicken H, Robinson DH, Wolf-Gladrow D, Dieckmann GS (1996) Modeling the heating and melting of sea ice through light absorption by microalgae. J Geophys Res 101/C1:1163-1181

Submitted: September 12, 2006; Accepted: December 8, 2006 Proofs received from author(s): May 15, 2007 